\title{
Analysis of The Pivot Point for a Turning Ship
}

\section{Ching-Yaw Tzeng}

Associate Professor, Institute of Maritime Technology, National Taiwan Ocean University, Keelung, Taiwan, ROC.

Follow this and additional works at: https://jmstt.ntou.edu.tw/journal

Part of the Engineering Commons

\section{Recommended Citation}

Tzeng, Ching-Yaw (1998) "Analysis of The Pivot Point for a Turning Ship," Journal of Marine Science and Technology. Vol. 6: Iss. 1, Article 5.

DOI: $10.51400 / 2709-6998.2518$

Available at: https://jmstt.ntou.edu.tw/journal/vol6/iss1/5

This Research Article is brought to you for free and open access by Journal of Marine Science and Technology. It has been accepted for inclusion in Journal of Marine Science and Technology by an authorized editor of Journal of Marine Science and Technology. 


\title{
ANALYSIS OF THE PIVOT POINT FOR A TURNING SHIP
}

\author{
Ching-Yaw Tzeng*
}

Keywords: Pivot point, Turning maneuver, Hydrodynamic coefficient, Linearized maneuvering equations.

\begin{abstract}
An approximate method based on the steady state linearized sway-yaw equations is proposed to estimate the pivot point of a turning ship. The location of the pivot point is directly related to the ratio of the "sway-rudder" and "yaw-rudder" gain coefficients, which can be readily computed from six linear hydrodynamic coefficients. Hence, estimation of the pivot point for a ship at the design stage is made possible with minimum hydrodynamic coefficients information required. Numerical results indicate that based on the proposed method, the estimated pivot point position for a turning ship correlates well with the solution obtained from a full nonlinear differential equations of motion-based analysis, where some forty hydrodynamic coefficients are involved. Existence of similar pattern in the sway speed $v$ and yaw rate $r$, known as the cancellation effect in a turning maneuver significantly extends the applicability of the proposed steady condition-based approach. Specifically, the ratio $\mathrm{v} / \mathrm{r}$ that defines the pivot point reaches a steady value long before the ship reaches the steady state phase of the turning.
\end{abstract}

\section{INTRODUCTION}

Pivot point is of special interest for pilots who actually involved in handling of ships. Since it is often necessary to conduct turning maneuver to avoid possible collision incidents near coastal waters or in harbors, where typically, limited space is available for maneuvering [1]. As the ship turns about the pivot point, it needs more space to turn if the pivot point is not located near midship. Specifically, for a ship of length $L$, if the pivot point is located at midship, the swept path required is about $\pi \cdot\left(\frac{L^{2}}{4}\right)$. However, it takes four times as large swept path if the pivot point is located at the bow.

Paper Received June, 1997. Revised March, 1998. Accepted March, 1998. Author for Correspondence: Ching-Yaw Tzeng.

*Associate Professor, Institute of Maritime Technology, National Taiwan Ocean University, Keelung, Taiwan, ROC.
It is well known to the pilots that the pivot point of a turning ship is located at about $1 / 5 \sim 1 / 4$ ship length aft bow[3]. The pivot point is defined as a point $X_{p}$ measured from the center of gravity of the ship that satisfies the relationship $v+X_{p} * r=0$, where $\mathrm{r}$ is the yaw rate and $v$ is the sway speed at the center of gravity of the ship. The pivot point is therefore characterized by a zero drift angle. Namely, forward of the pivot point, the inflow appears to come from one side of the ship; aft of the pivot point, the inflow appears to come from the other side of the ship [2].

Simulations based on nonlinear equations of motion has been adopted in studying the pivot point under various environmental, and operating conditions [4]. Slender body theory has also been employed in estimating of the pivot point analytically and it is concluded that under simplified assumptions, the pivot point is indeed located near the bow [5].

In this paper, linearized sway and yaw equations are employed to analytically estimate the pivot point of a turning ship. Steady state condition-based explicit formula relating the linear hydrodynamic coefficients to the location of the pivot point will be derived. Hence, it is possible to estimate the pivot point of a ship at the design stage with minimal amount of information on the linear hydrodynamic coefficients, which can be obtained from captive model test [2].

\section{SYSTEM DESCRIPTION}

It is well known that to fully represent a rigid body motion in space requires a six-degree-of-freedom description. However, for ship maneuvering study, it is usually assumed that the steering of a ship can be regarded as horizontal plane rigid body motion; namely, a three-degree-of freedom motion. This assumption holds as long as the corresponding sea state is not too rough and the turning maneuver induced rolling is not significant. Since we will be studying the turning motion of a VLCC and a Mariner class vessel in calm sea conditions, the above assump- 
tions are met.

\section{Nonlinear Model}

The equations of motion describing the steering dynamics of a ship are readily obtained from Newton's law in space-fixed coordinate $x_{0}-y_{0}$ (see Fig. 1). However, to take advantage of the symmetry property of a ship, a ship-fixed coordinate system $x-y$ is preferred. with the origin for the axis system taken at the center of gravity of the ship, the steering equations of motion within the ship-fixed coordinate system can be written as

$$
\begin{aligned}
& m(\dot{u}-v r)=X, \\
& m(\dot{v}+u r)=Y, \\
& I \dot{r}=N,
\end{aligned}
$$

where

$m$ is the mass of the ship,

$u$ is the surge speed; namely, the speed in the $x$ direction,

$v$ is the sway speed; namely, the speed in the $y$ direction,

$r$ is the yaw rate; namely, the angular rate about the vertical axis,

$I$ is the moment of inertia of the ship about the vertical axis,

$X$ is the force applied on the ship in the $x$ direction,

$Y$ is the force applied on the ship in the $y$ direction,

$N$ is the moment applied on the ship about the vertical axis.

The forces $X, Y$, and moment $N$ can be expressed as functions of the states $u, v, r$, their time derivatives $\dot{u}, \dot{v}, \dot{r}$ and the rudder angle $\delta$. Hence,

$$
\begin{aligned}
& X=X(u, v, r, \dot{u}, \dot{v}, \dot{r}, \delta), \\
& Y=Y(u, v, r, \dot{u}, \dot{v}, \dot{r}, \delta), \\
& N=N(u, v, r, \dot{u}, \dot{v}, \dot{r}, \delta) .
\end{aligned}
$$

Taylor series expansions up to 3rd order in terms of the state variables $u, v, r \ldots$ have been suggested to represent Eqs. (2) as follows[2]:

$$
\begin{aligned}
X & =X_{0}+X_{\dot{u}} \dot{u}+X_{u} u+\mathrm{X}_{u u} u^{2}+\mathrm{X}_{u u u} u^{3}+X_{v v} v^{2} \\
& +X_{\delta \delta} \delta^{2}+\mathrm{X}_{r r} r^{2}+X_{v r} v r+X_{v \delta} v \delta+X_{r \delta} r \delta \\
& +X_{\delta \delta u} \delta \delta u+X_{r r u} r^{2} u+X_{v v u} v^{2} u+X_{v r u} v r u \\
& +X_{v \delta u} v \delta u+X_{r \delta u} r \delta u
\end{aligned}
$$

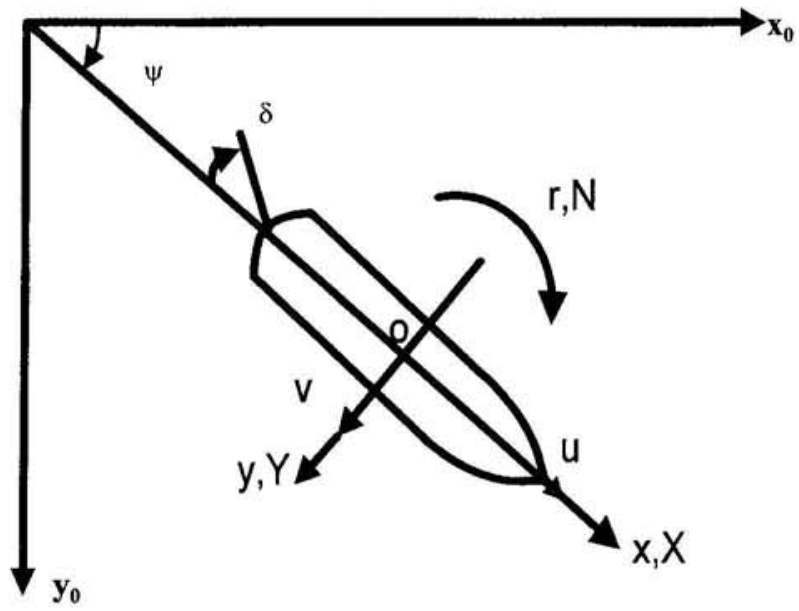

Fig. 1. Definition of Motions in the Horizontal Plane.

$$
\begin{aligned}
Y & =Y_{0}+Y_{\dot{v}} \dot{v}+Y_{\dot{r}} \dot{r}+Y_{v} v+Y_{r} r+Y_{\delta} \delta+Y_{v u} v u \\
& +Y_{r u} r u+Y_{\delta u} \delta u+Y_{v v v} v^{3}+Y_{r r r} r^{3}+Y_{\delta \delta \delta} \delta^{3} \\
& +Y_{v r r} v r^{2}+Y_{v \delta \delta} \delta^{2}+Y_{v u u} v u^{2}+Y_{r v v} r v^{2}+Y_{r \delta \delta} r \delta^{2} \\
& +Y_{r u u} r u^{2}+Y_{\delta v v} \delta v^{2}+Y_{\delta r r} \delta r^{2}+Y_{\delta u u} \delta u^{2} \\
& +Y_{v r \delta} v r \delta \\
N & =N_{0}+N_{\dot{v}} \dot{v}+N_{\dot{r}} \dot{r}+N_{v} v+N_{r} r+N_{\delta} \delta+N_{v u} v u \\
& +N_{r u} r u+N_{\delta u} \delta u+N_{v v v} v^{3}+N_{r r r} r^{3}+N_{\delta \delta \delta} \delta^{3} \\
& +N_{v r r} v r^{2}+N_{v \delta \delta} v \delta^{2}+N_{v u u} v u^{2}+N_{r v v} r v^{2}+N_{r \delta \delta} r \delta^{2} \\
& +N_{r u u} r u^{2}+N_{\delta v v} \delta v^{2}+N_{\delta r r} \delta r^{2}+N_{\delta u u} \delta u^{2} \\
& +N_{v r \delta} v r \delta,
\end{aligned}
$$

where $X_{u}, Y_{\delta}, N_{v} \ldots$ are the hydrodynamic derivatives. For example, $N_{v}=\partial N / \partial v$ stands for the derivative of the moment $N$ with respect to the sway speed $v$. These hydrodynamic derivatives can either be obtained from experimental model tests or from system identification techniques applied to measured ship trajectories [2].

\section{Linearized Model}

As the relationships between $X, Y, N$ and the state variables described by Eqs. (3) are too complicated. Taylor series expansion has been suggested to expand the right hand sides of Eqs. (2) while keeping only the linear terms[6]. Substitution of the expansion form into Eqs. (1) gives

$$
\begin{aligned}
m(\dot{u}-v r)= & X_{\delta} \delta+X_{u} u+X_{\dot{u}} \dot{u}+X_{v} v \\
& X_{\dot{v}} \dot{v}+X_{r} r+X_{\dot{r}} \dot{r}, \\
m(\dot{v}+u r)= & Y_{\delta} \delta+Y_{u} u+Y_{\dot{u}} \dot{u}+Y_{v} v \\
& Y_{\dot{v}} \dot{v}+Y_{r} r+Y_{\dot{r}} \dot{r}, \\
I \dot{r}= & N_{\delta} \delta+N_{u} u+N_{\dot{u}} \dot{u}+N_{v} v+N_{\dot{v}} \dot{v} \\
+ & N_{r} r+N_{\dot{r}} \dot{r} .
\end{aligned}
$$


Due to symmetry property of the ship, some of the hydrodynamic derivatives vanish[2]. Further linearizing the left hand sides of Eqs. (4) with respect to a straight line motion condition of constant surge speed $u_{0}$ gives

$$
\begin{aligned}
& m \dot{u}=X_{u} u+X_{\dot{u}} \dot{u}, \\
& m\left(\dot{v}+r u_{0}\right)=Y_{\delta} \delta+Y_{v} v+Y_{\dot{v}} \dot{v}+Y_{r} r+Y_{i} \dot{r}, \\
& I \dot{r}=N_{\delta} \delta+N_{v} v+N_{\dot{v}} \dot{v}+N_{r} r+N_{\dot{r}} \dot{r} .
\end{aligned}
$$

The equations of motion are greatly simplified after linearization being done; specifically the surge Eq. (5a) is decoupled from the sway Eq. (5b) and the yaw Eq. (5c). Eqs. (5b)-(5c) describe the lateral motion of a ship. Most ship steering autopilots design are based on the model described by Eqs. (5b)-(5c).

\section{Linearized Yaw Dynamics Model}

After elimination of the sway speed $v$ in Eqs. (5b)-(5c) yields

$$
T_{1} T_{2} \ddot{r}+\left(T_{1}+T_{2}\right) \dot{r}+r=K\left(\delta+T_{3} \delta\right),
$$

where $T_{1}, T_{2}, T_{3}$ are time constants and $K$ is the rudder gain relating the steady state yaw rate to the rudder input, which can be expressed in terms of the hydrodynamic derivatives

$$
\begin{aligned}
& T_{1} T_{2}=\frac{\left(I-N_{\dot{r}}\right)\left(m-Y_{\dot{v}}\right)-N_{\dot{v}} Y_{\dot{r}}}{D}, \\
& T_{1}+T_{2} \\
& =\frac{-\left(I-N_{\dot{r}}\right) Y_{v}-\left(m-Y_{\dot{v}}\right) N_{r}+\left(m u_{0}-Y_{r}\right) N_{\dot{v}}-Y_{\dot{r}} N_{v}}{D}, \\
& K=-\left(\frac{Y_{v} N_{\delta}-N_{v} Y_{\delta}}{D}\right), \\
& K T_{3}=\frac{-\left(m-Y_{\dot{v}}\right) N_{\delta}-N_{\dot{v}} Y_{\delta}}{D},
\end{aligned}
$$

where

$$
D=\left(m u_{0}-Y_{r}\right) N_{v}+N_{r} Y_{v}
$$

The transfer function corresponding to Eq. (6a) is readily obtained as

$$
\frac{r}{\delta}=\frac{K\left(1+s T_{3}\right)}{\left(1+s T_{1}\right)\left(1+s T_{2}\right)}
$$

Equation (7) defines the input-output relation- ship between the yaw rate $\mathrm{r}$ and the rudder angle $\delta$. Namely Eq. (7) characterizes the yaw dynamics of a ship.

\section{Linearized Sway Dynamics Model}

After elimination of the yaw rate $r$ in Eqs. (5b)(5c) yields

$$
T_{1} T_{2} \ddot{v}+\left(T_{1}+T_{2}\right) \dot{v}+v=K_{v}\left(\delta+T_{v} \dot{\delta}\right),
$$

where $T_{1}, T_{2}, T_{v}$ are time constants and $K_{v}$ is the rudder gain relating the steady state sway speed to the rudder input. $T_{1}, T_{2}$ are defined by the same relationships described in Eqs. (6b)-(6c). $K_{v}$ and $T_{v}$ are defined by the following relations

$$
\begin{aligned}
& K_{v}=-\frac{\left(m u_{0}-Y_{r}\right) N_{\delta}+N_{r} Y_{\delta}}{D}, \\
& K_{v} T_{v}=\frac{\left(I-N_{r}\right) Y_{\delta}+N_{r} Y_{\delta}}{D},
\end{aligned}
$$

where $D$ is defined as in Eq. (6f). The transfer function corresponding to Eq. ( $8 \mathrm{a}$ ) is readily obtained as

$$
\frac{v}{\delta}=\frac{K_{v}\left(1+s T_{v}\right)}{\left(1+s T_{1}\right)\left(1+s T_{2}\right)} .
$$

\section{PIVOT POINT ANALYSIS}

The pivot point is defined as a point $X_{p}$ measured from the center of gravity of a ship that satisfies the following relationship

$$
v+X_{p} \cdot r=0,
$$

where $v$ is the sway speed at the center of gravity of the ship, $r$ is the yaw rate. Specifically, due to combination of side motion and the rotation, causes the ship to appear to rotate about a point, which is generally known as the pivot point.

\section{Measured Data-Based Analysis}

It is possible to estimate the pivot point $X_{p}$ from Eq. (10) if measurements on the yaw rate $r$ and the sway speed $v$ are available. Practically, this can be done on board a ship with a dual-axis Doppler speed $\log$ in conjunction with a rate gyro. Consequently, it follows from Eq. (10) that

$$
X_{p}=-v / r \text {. }
$$


Note that Eq. (11) is ill defined when the yaw rate $\mathrm{r}$ is zero, which corresponds typically to a straight line motion. Actually, when the ship is moving on a straight line or in a pure sway motion, it is reasonable to consider the pivot point being located at infinity. As the ship initiates a turning maneuver, the yaw rate $r$ built up slowly, a larger error is likely to happen when using Eq. (11) in evaluating the pivot point especially for the period before completion of rudder movement.

A well-tuned VLCC ownship model built by Krupp-Atlas Company for the ship handling simulator of National Taiwan Ocean University is chosen as a real ship and the simulated sway and yaw information are treated as data measured on board a real ship. Figs. 2A-2B show the measured sway sped $\mathrm{v}$ and the yaw rate $r$ for the VLCC for a 35 deg turning maneuver. Pivot point computed with Eq. (11) is shown in Fig. 2C, and it is observed that during the $35 \mathrm{deg}$ turning maneuver, the pivot point moves from midship to about $1 / 5$ ship length aft bow.

After examing Figs. 2A-2C, it is interesting to note that the pivot point settles down to a fixed value long before the sway speed and the yaw rate do. Namely, the pivot point reaches a steady state value while the ship is still in the transient phase of the turning maneuver. Specifically, the pivot point reaches a steady value in 4 minutes after initiating the turning maneuver; however, it takes twice as long before the ship reaches the steady state turning condition. This phenomenon can be attributed to the cancellation effect between the sway and yaw induced side forces [7].

\section{Nonlinear Maneuvering Equations-Based Analysis}

If all the hydrodynamic coefficients appeared in the nonlinear maneuvering equations described by Eqs. (1)-(3) are available, it is possible to obtain the sway speed $v$ and the yaw rate $\mathrm{r}$ numerically via the differential equation solver. Hence, Eq. (11) can be readily applied in finding the pivot point. Since the Mariner class vessel has been extensively studied, the corresponding hydrodynamic coefficients are well documented. Specifically, the hydrodynamic coefficients corresponding to a speed of $15 \mathrm{kts}$ are employed in this study in simulating the 35 deg turning maneuver.

After solving for Eqs. (1)-(3), the sway speed $\mathrm{v}$ and the yaw rate $r$ of the Mariner class vessel during a 35 deg turning maneuver with an initial speed of 15 kts are given in Figs. 3A-3B. The pivot point calculated with Eq. (11) is given in Fig. 3C. It is seen that the pivot point shifts from midship to 0.13 ship length

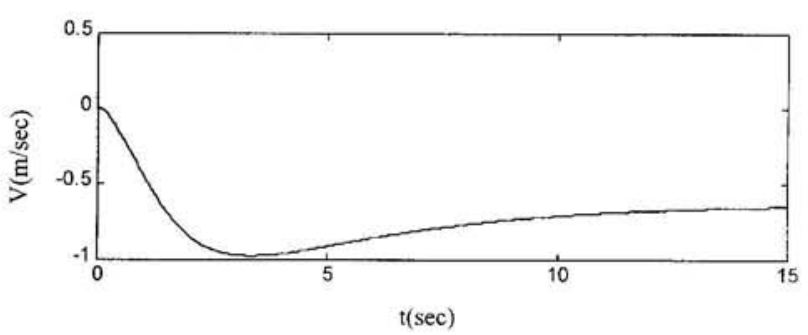

(a)

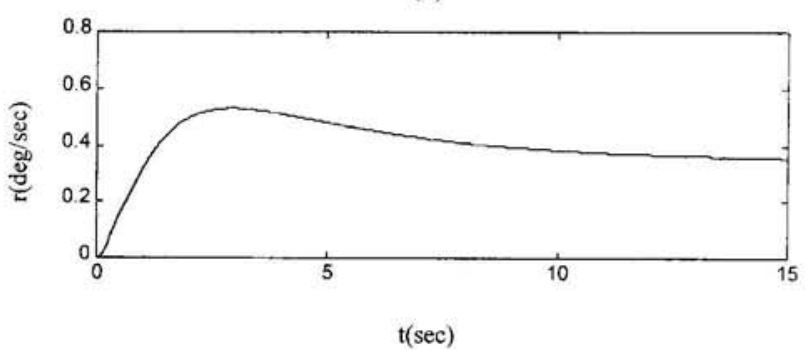

(b)

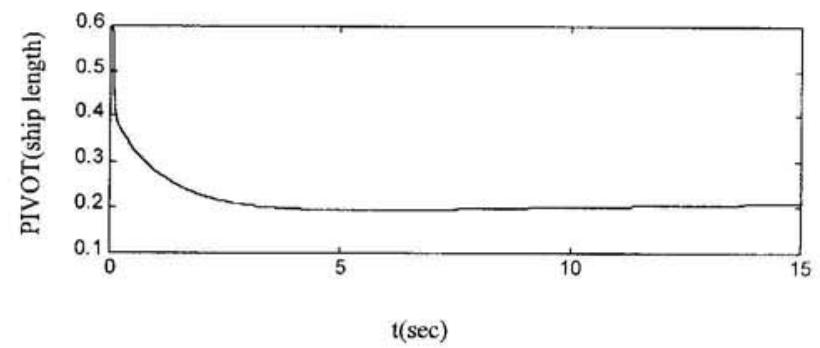

(c)

Fig. 2. (a) Sway velocity, VLCC 35 deg turn. (b) Yaw rate, VLCC 35 deg turn. (c) Pivoting position, Aft-Bow, VLCC 35 deg turn.

aft bow during a 35 deg turning maneuver. Once again, due to the cancellation effect previously described, the pivot point reaches a steady value long before the ship reaches the steady state phase of the turning maneuver. Specifically, it takes $70 \mathrm{sec}$ for the pivot point to reach a steady state value; however it takes twice as long for the ship to enter into the steady state phase of the turning maneuver. In summary, Eqs. (1)-(3) are solved numerically by standard differential equation solver for a 35 deg. turning maneuver, and this is how Fig. 3A (sway speed $v$ ) and Fig. 3B (yaw rate r) are obtained. The pivot point is then found by algebraically solving the pivot point definition equation (Eq. (11), $X_{p}=-v / r$ ). Here, $X_{p}$ defines the pivot point, and this is how Fig. $3 \mathrm{C}$ is obtained. It is also to be noted that it is impossible to find an explicit formula of the pivot point for the nonlinear analysis; consequently, no such formula is presented in the paper. Since in the nonlinear analysis the sway speed $\mathrm{v}$ and the yaw rate $r$ can only be found numerically via nonlinear differential equation solver, then the pivot point is obtained from the definition 


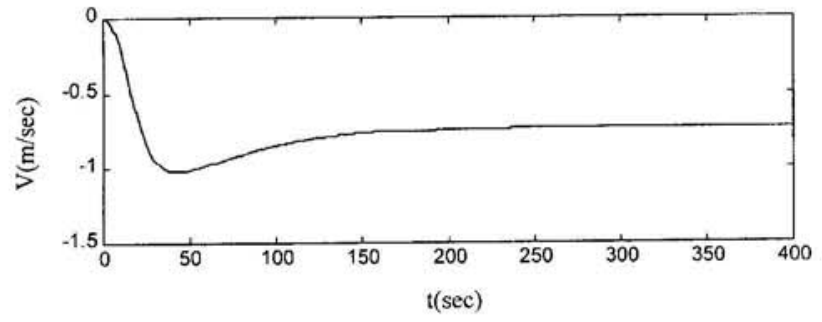

(a)

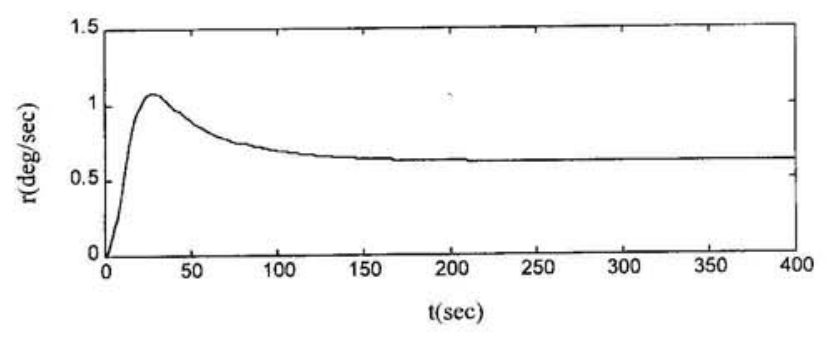

(b)

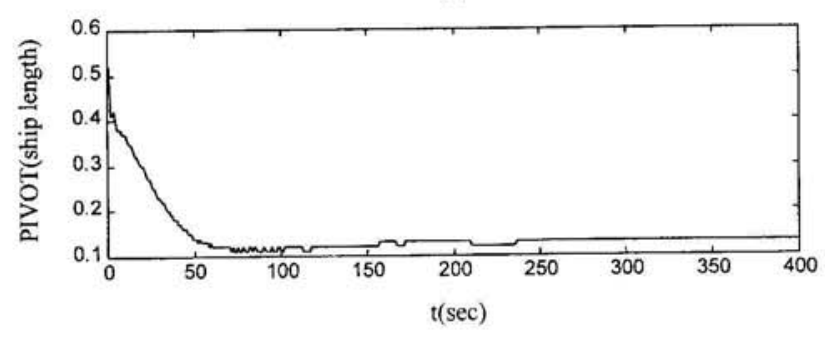

(c)

Fig. 3. (a) Sway velocity, Mariner 35 deg turn. (b) Yaw rate, Mariner 35 deg turn. (c) Pivoting position, Aft-Bow, Mariner 35 deg turn.

equation $v+X_{p} \bullet r=0$.

\section{Steady State Linear Sway-Yaw Equations-Based Analysis}

As can be seen from Fig. $2 \mathrm{C}$ and Fig. 3C, the pivot point settles down to a fixed value shortly after initialization of the turning motion. Hence, it seems possible to estimate the pivot point with the steady state formulation, while employing only a minimum amount of hydrodynamic coefficients. Specifically, divided Eq. (9) by Eq. (7), we have

$$
\frac{v}{r}=\frac{K_{v}\left(1+s T_{v}\right)}{K\left(1+s T_{3}\right)}
$$

It is well known from the Laplace transform that, " $s \rightarrow 0$ corresponds to the steady state condition $t \rightarrow$ $\infty "$. Hence

$$
\frac{v_{(s . s)}}{r_{(s . s)}}=\frac{K_{v}}{K},
$$

Table 1. Nondimensional Linear Hydrodynamic Coefficients, Mariner Class Vessel [8]

\begin{tabular}{cc}
\hline$N_{r}^{\prime}$ & $-166^{*} 10^{-5}$ \\
\hline$N_{y}^{\prime}$ & $-264 * 10^{-5}$ \\
$N_{\delta}$ & $-139 * 10^{-5}$ \\
$Y_{\delta}^{\prime}$ & $278^{-5} 10^{-5}$ \\
$Y_{r}^{\prime}-\mathrm{m}^{\prime}$ & $-499 * 10^{-5}$ \\
$Y_{v}^{\prime}$ & $-1160 * 10^{-5}$ \\
\hline
\end{tabular}

with Eq. (11), it follows that

$$
X_{p(s . s)}=-\frac{K_{v}}{K},
$$

where s.s. represents the "steady state" condition. Further simplification is achieved by substituting Eqs. (6d) and (8b) into Eq. (14) to give

$$
X_{p(s . s)}=-\frac{N_{r} Y_{\delta}-\left(Y_{r}-m u_{0}\right) N_{\delta}}{Y_{v} N_{\delta}-N_{v} Y_{\delta}}
$$

As the hydrodynamics coefficients are usually expressed in non-dimensionalized form [2], Eq. (15) can be further simplified into non-dimensionalized form

$$
X_{p(s . s)}^{\prime}=-\left(\frac{N_{r}^{\prime} Y_{\delta}^{\prime}-\left(Y_{r}^{\prime}-m^{\prime}\right) N_{\delta}^{\prime}}{Y_{v}^{\prime} N_{\delta}^{\prime}-N_{v}^{\prime} Y_{\delta}^{\prime}}\right),
$$

where $N_{r}^{\prime} N_{v}^{\prime}$... are the non-dimensionalized coefficients. For example, $N_{v}^{\prime}$ is defined by

$$
N_{v}^{\prime}=\frac{N_{v}}{\frac{\rho}{2} L^{3} u_{0}},
$$

where $\rho$, is the density of water, $L$ is the ship length, $u_{0}$ is the ship speed, and $X_{p(s . s)}^{\prime}$ is normalized by the length of the $\operatorname{ship} L$, namely,

$$
X_{p(s . s)}^{\prime}=\frac{X_{p(s . s)}}{L} \text {. }
$$

With the nondimensionalized hydrodynamic coefficients of a Mariner class vessel given in Table 1 [8]. It is straightforward to find from Eq. (16) that $X_{p(s . s)}^{\prime}=0.4923$. Namely, the pivot point during the steady state phase of the turning maneuver is located at $0.4923 \mathrm{~L}$ ahead of the center of the gravity, where $\mathrm{L}$ is the length of the ship. Since the center of gravity of the ship is located at $0.023 \mathrm{~L}$ aft midship. The pivot point is therefore located at $0.10 \mathrm{~L}$ aft bow. This value is not far from the value $0.13 \mathrm{~L}$ computed from the previously discussed nonlinear maneuvering equations-based approach, where some forty hydrodynamic coefficients are required in the 
analysis.

\section{CONCLUSIONS}

An approximate method based on the linearized steady state sway and yaw equations has been suggested in estimating the pivot point of a turning ship at the design stage. Analysis of a Mariner class vessel indicates that the proposed approximate method achieves acceptable accuracy when compared with results obtained from a full nonlinear differential equations-based analysis. However, more numerical examples need to be carried out before quantitative performance evaluation of the proposed method can be established. It is observed that the pivot point of a turning ship settles down to a constant value long before the ship enters into the steady state phase of the turning motion. Hence, the proposed steady state condition-based method seems to extend its applicability into the latter half of the transient phase of the turning maneuver.

\section{REFERENCES}

1. Crenshaw, R.S., Naval Shiphandling, United States Naval Institute, Maryland (1976).

2. Lewis, E.V, Editor, "Principles of Naval Architecture, Vol. 3, Motions in Waves and Controllability," SNAME, NJ (1989).

3. Paffett, J.A.H., "Turning Corners and ManeuveringThe Forces on a Ship," The Nautical Institute of Pilotage and Ship Handling, London, UK. pp. 256259 (1990).

4. Inoue K, Jiang J.M., and Ishihata S., "Estimation the Position of the Pivot Point in Ship Handling and Analysing its Characteristics," Journal of Socienty of Navigation, Japan, No. 89, pp. 39-49 (1993).

5. Hwang, W.Y., "Application of System Identificaton to Ship Maneuvering," PhD Thesis, Massachusetts
Institute of Technology, MA (1980).

6. Fossen, T.I., Guidance and Control of Ocean Vehicles, John Willey and Sons, NY (1994).

7. Hwang, W.Y. "Cancellation Effect and Parameter Identifiablilty of Ship Steering Dynamics," International Shipbuilding Progress, Vol. 26. No. 332, pp. 90-120 (1982).

8. Chislett, M.S. and Strom-Tejsen, J., "Planar Motion Mechanism Tests and Full Scale Steering and Maneuvering Predictions for a Mariner Class Vessel," Tech. Rept. Hy-6, Hydrodynamic and Aerodynamic Laboratory, Denmark (1965).

\section{船體迴旋運動樞紐點之分析 \\ 曾 慶 耀}

海洋大學航運技術研究所副教授

$$
\text { 摘 要 }
$$

本文提出一依據稳態線性横移及平擺公式推 導之近似法, 分析船體迴旋運動時之樞紐點位置, 該位置主要和“横移-舵”及“平擺-舵”增益係數 之比值有關。而增益係數可經由六個線性流力係數 計算而得之。經由寞驗計算顯示, 以本文所提之近 似代数法估算之樞紐點位置, 與依據用近四十個流 力係数資料之非線性微分方程船舶模式分析所得結 果比較, 顯示仍保有合理之精確度。由於在船體迥 旋運動時, 横移及平揟量具有十分相似之變化趨 勢, 此即所謂抵消效應。因此踓然横移及平揟個別 量尚未達䊝定值, 但決定樞紐點位置之横移平擺比 值卻已達穞定值。此一特性大幅提高本文提出䊝態 近似幾解析法之適用時機。 